\title{
Effect of Supercharging \& Injection Pressure on Engine Performance Characteristic of Jatropha Biodiesel Blend
}

\author{
Harsh G Chaudhari ${ }^{1}$, Dr. Tushar M Patel ${ }^{2}$, Prof. Pragna R Patel ${ }^{3}$ \\ ${ }^{1 *}$ M.E. Scholar, Mechanical Engineering Department, LDRP-ITR, Gandhinagar, Gujarat, India. \\ ${ }^{2}$ Professor, Mechanical Engineering Department, LDRP-ITR, Gandhinagar, Gujarat, India. \\ ${ }^{3}$ AssistantProfessor, Mechanical Engineering Department, LDRP-ITR, Gandhinagar, Gujarat, India.
}

\begin{abstract}
In the present investigation experimental work will be carrying out to estimate the performance characteristics of a single cylinder, four stroke variable compression ratio multi fuel engine fueled with Jatropha biodiesel blended with standard diesel. Tests have been conducted using the biodiesel blends of 10ODOB, 50D5OB, OD100B where diesel is denoted by $D$ and Jatropha biodiesel is denoted by B, with compression ratio 18 and an engine speed of $1500 \mathrm{rpm}$ at different loading conditions. Present paper deals with effect of supercharging on engine performance characteristic. Paper deals with effects on engine fueled with diesel, blend of diesel with biodiesel with a view to provide a platform for comparison of the parameter on blended Jatropha fuels. The performance parameters includes brake thermal efficiency (BThEff.), indicated thermal efficiency (IThEff.), specific fuel consumption (SFC), brake power (BP), indicated power (IP), torque $(T)$, indicated mean effective pressure (IMEP), air to fuel ratio $(A / F)$ and mechanical efficiency. In it result found thatoptimum specific fuel consumption were obtained for D0B100 when engine run at supercharged condition compared to diesel. The Brake thermal efficiency of DOB100 Jatropha biodiesel blend is more among all other blends. The mechanical efficiency of all blends are less than diesel fuel but the D50B50 blend have highest mechanical efficiency at engine supercharging condition.
\end{abstract}

Keyword: Diesel Engine, Jatropha biodiesel, Biofuels, Blending, Supercharging, Performance Characteristic, Injection Pressure, Inlet Air pressure.

\section{Introduction}

The constant increment in the rate of utilization of the fossil fuels, depend upon the regularly increasing in population and the urbanization in the present day world has made the consumption of these ordinary fuel resource in the near future a very unavoidable truth. Also, the greenhouse gas outflows from these fossil fuels are continually degrading the planet and bringing about an earth wide temperature increase and other environment related issue. Thusly, the circumstance requests for a substitute alternate source of energy that can be utilized to overcome the forecasted future energy emergency. Notwithstanding this, if the energy source is clean and renewable it will lessen the natural issues too [2]. In this mission for a substitute and renewable energy sources researchers have found that biodiesel-diesel mixes as option fuels has turned into a famous alternative fuels. This is because researchers have seen that the properties of biodiesel prepared from vegetable oils are near to pure diesel and in this way it has a promising future as an optional fuel for diesel engine. Biodiesel is as an optional fuel got from vegetable (green) oil or animal fats are oxygenated, bio de-gradable, non-harmful and earth safe [8]. Biodiesel's are classified into two categories as eatable and non-eatable. Eatable oils are such that sunflower, corn, rapeseed, palm, and soybean and waste vegetable oils. The non-eatable oils are such that Jatropha, Karanja, Polanga oils and likes [10]. Expanding sympathy toward ecological contamination alongside keeping up performance of diesel engines has prompted broad research in area of fuel. Among different choices researched for diesel fuel, biodiesel has ended up being most reasonable for diesel engines [11]. Different research works have proved that performance of biodiesel is almost like diesel engines with less discharges. Further engine parameters for example Compression Ratio, Injection Timing and Injection Pressure are likewise observed to be significant factors contributing on the performance and emission parameter of diesel engine fueled with biodiesel [13]. Present paper focuses on effect of parameter viz. inlet air pressure and injection pressure.In it practical two different condition for finding the best result of C.I. Engine using Jatropha biodiesel.(1) Normal condition (2) Supercharging condition. The paper provides a platform for comparison of effect of varying load on performance of engine fueled by (a) $100 \%$ diesel (b) Blend of diesel \& Biodiesel (c) 100\% Biodiesel.

\section{Literature Review}

Rao et al (2009) they studied on the utilization of Jatropha oil methyl ester and its mixes as an option fuel in diesel engine. Comes about showed that B25 has nearer performance to diesel and B100 has bring down brake thermal effectiveness, predominantly because of its high density contrasted with diesel. The brake thermal 
productivity of biodiesel and its mixes was observed to be marginally higher than that of diesel fuel at tried load conditions and there was no distinction between the biodiesel and its mixed fuel efficiencies [2].Chaudhari et al (2016) they researched on performance of small capacity compression ignition engine using Jatropha biodiesel blends. In their experiment engine was run at default set compression ratio of 17.5 and injection pressure of 180 bar. Highest thermal efficiency was found for B20 v/v blend, which was $26.43 \%$ while other blend B30 shown similar thermal efficiency compare to diesel but was lower than B20. Emission of engine running with biodiesel was almost similar to that of diesel and there was no significant difference observed. They concluded that lower blend ratio of biodiesel can be successfully used for diesel engine without modification [15].EL-Kasaby $M$ et al (2013) they examined on trial examinations of start postpone period and performance of a diesel engine worked with Jatropha oil biodiesel. It has been demonstrated that B50 (half of biodiesel in a blend of biodiesel and diesel fuel) gives the most elevated pinnacle weight at 1750 RPM, while B10 gives the most noteworthy pinnacle weight at low speed, 1000 RPM. B50 indicates likewise, the most noteworthy BSFC by around (12.5-25\%) contrasted and diesel fuel. B10 gives the most noteworthy brake thermal effectiveness. B50 to B30 demonstrate about the most reduced CO fixation, other than CO focus is the most elevated at both sit still and high running rates [9].

After observing literature review we concluded that, to find out the other option like alternative fuel that can be used and get energy from it. For higher performance, engine must be modified. When alternative fuel is used as a blend with diesel than there must have to do optimization of parameter which one directly or indirectly effect on the performance of the engine. From above survey, researcher took Jatropha fuel as a blend and optimize one parameter which affect the performance of the engine. The performance characteristics have been analyzed and compared to baseline diesel fuel.

\section{Jatropha Oil}

The performance and emission characteristics of biodiesel fueled engine depend purely upon the thermo physical properties of the biodiesel [9]. Since Jatropha oil can be grown in wastelands, its cultivation to biodiesel production can also generate a large scale employment in a country like India. Basically the biodiesels are derived from vegetable oils via a popular process, transesterification in the presence of a catalyst and alcohol as a reactant [7]. Due to the availability and cost factor methyl alcohol is commonly used and the derived biodiesel is also known as fatty acid methyl ester. The purpose of the transesterification process is to lower the viscosity of the oil.

Table 3.1 Comparison of property Jatropha biodiesel vs Diesel [10]

\begin{tabular}{|l|l|l|l|}
\hline Sr. no. & Properties & Jatropha biodiesel & Diesel \\
\hline 1 & Colour & Golden yellow & Orange \\
\hline 2 & Mass fraction $(\%)$ & & \\
\hline & Carbon & 0.766 & 0.87 \\
\hline & Hydrogen & 0.121 & 0.126 \\
\hline & Oxygen & 0.113 & 0.004 \\
\hline 4 & Density at $323 \mathrm{~K}\left(\mathrm{~kg} / \mathrm{m}^{3}\right)$ & 862 & 830 \\
\hline 5 & Specific gravity at $30^{0} \mathrm{C}$ & 0.886 & 0.84 to 0.88 \\
\hline 6 & Gross calorific value $(\mathrm{Mj} / \mathrm{Kg})$ & 41 & 42 \\
\hline 7 & Kinematic viscosity, Cst@ $40{ }^{0} \mathrm{C}$ & 4.20 & 2 \\
\hline 8 & Cetane number & $57-62$ & 55 \\
\hline 9 & Boiling point ${ }^{0} \mathrm{C}$ & 286 & 248 \\
\hline 10 & Solidifying point ${ }^{\circ} \mathrm{C}$ & -10 & -14 \\
\hline
\end{tabular}

\section{Experimental Setup And Method}

\subsection{Experimental Setup}

The setup consists of single cylinder, four stroke, multi-fuel, research engine connected to eddy type dynamometer for loading. The operation mode of the engine can be changed from diesel to Petrol and from Petrol to Diesel with some necessary changes. In both modes the compression ration can be varied without stopping the engine and without altering the combustion chamber geometry by specially designed tilting cylinder block arrangement. The injection point and spark point can be changed for research tests [16]. Setup is provided with necessary instruments for combustion pressure, Diesel line pressure and crank-angle measurements. These signals are interfaced with computer for pressure crank-angle diagrams. Instruments are provided to interface airflow, fuel flow, temperatures and load measurements. The setup has stand-alone panel box consisting of air box, two fuel flow measurements, process indicator and hardware interface [17]. Rota meters are provided for cooling water and calorimeter water flow measurement. A battery, starter and battery charger is provided for engine electric start arrangement [18]. 
The setup enables study of VCR engine performance for brake power, indicated power, frictional power, BMEP, IMEP, brake thermal efficiency, indicated thermal efficiency, Mechanical efficiency, volumetric efficiency, specific fuel consumption, A/F ratio, heat balance and combustion analysis. Lab view based Engine Performance Analysis software package "Engine soft" is provided for on line performance evaluation [19].

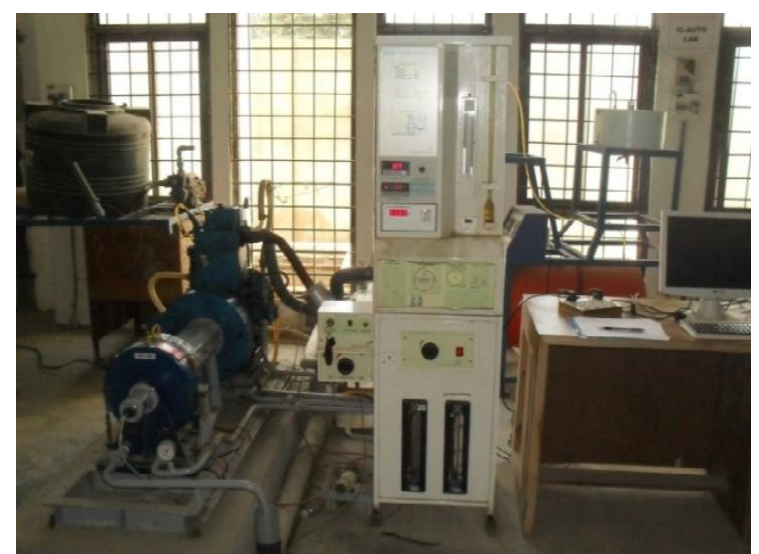

Fig 4.1 Front view of experimental setup

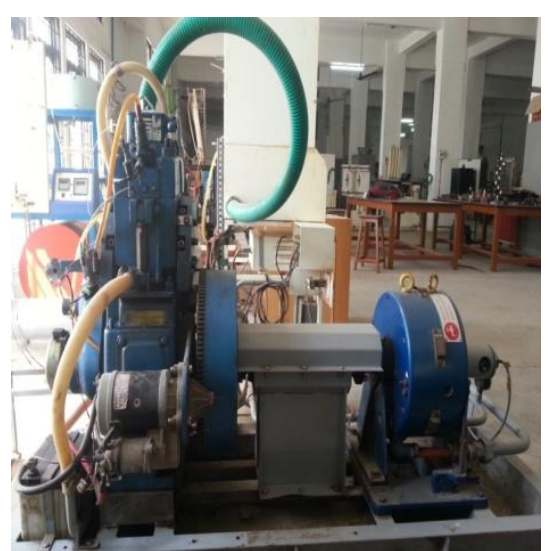

Fig 4.2 Side view of experimental setup

Table 4.1 Technical specifications [20]

\begin{tabular}{|l|l|}
\hline Engine manufacturer & Apex Innovations (Research Engine test set up) \\
\hline Software & Engine soft Engine performance analysis software \\
\hline Engine type & Single cylinder four stroke multi fuel research engine \\
\hline No. of cylinder & 1 \\
\hline Type of cooling & Water cooled \\
\hline Rated Power & $3.5 \mathrm{~kW} \mathrm{@} 1500 \mathrm{rpm}$ \\
\hline Cylinder diameter & $87.5 \mathrm{~mm}$ \\
\hline Orifice diameter & $20 \mathrm{~mm}$ \\
\hline Stroke length & $110 \mathrm{~mm}$ \\
\hline Connecting rod length & $234 \mathrm{~mm}$ \\
\hline Dynamometer & Type: eddy current, water cooled, with loading unit \\
\hline
\end{tabular}

\subsection{Experimental Methodology}

In this experiment, diesel engine is used and connected with the rope break dynamometer, with the help of dynamometer, vary the load on the engine or remain constant .Gas analyzer is used to find the emission characteristic of exhaust gas. The reading takes by constant load or by varying the load on the engine using the dynamometer. Engine performance such as break power, indicated power, break specific fuel consumption etc. are found from the experiments. First of all experimental set up is developed to fulfil the objective and it contains single cylinder diesel engine. Inlet air pressure $\&$ injection pressure are taken for the optimization for same compression ratio at different load. We used two different condition for finding the best result of C.I. Engine using Jatropha biodiesel. [1] Normal condition- In its first condition engine take atmospheric air as an inlet air. [2] Supercharging condition- In it engine take continuous flow of air with the use of air compressor as an external device.Take the Measurement using pure diesel, blended diesel \& bio-diesel fuel at different load condition, different injection pressure for the two condition \& measure the performance and emission of C.I. Engine. Emission reading is also taken by gas analyser equipment for emission analysis purpose.

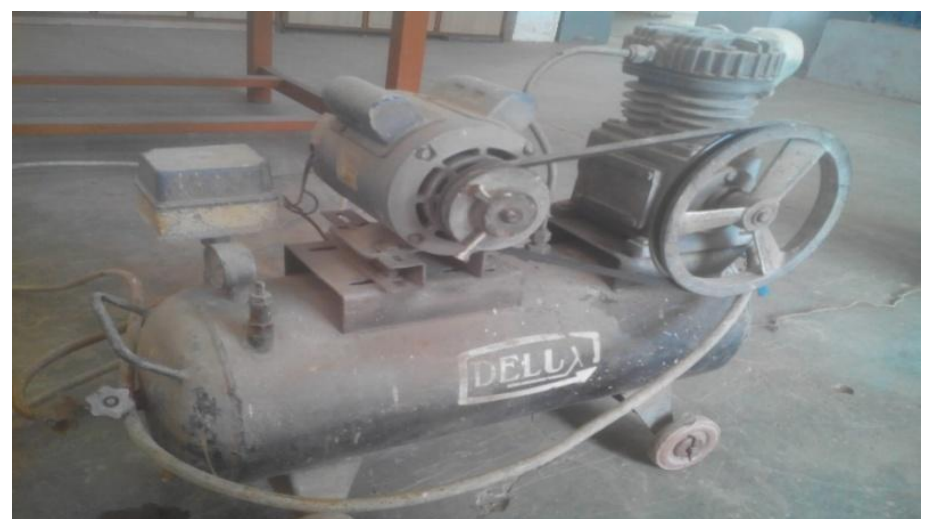

Fig 4.2.1 Air compressor 


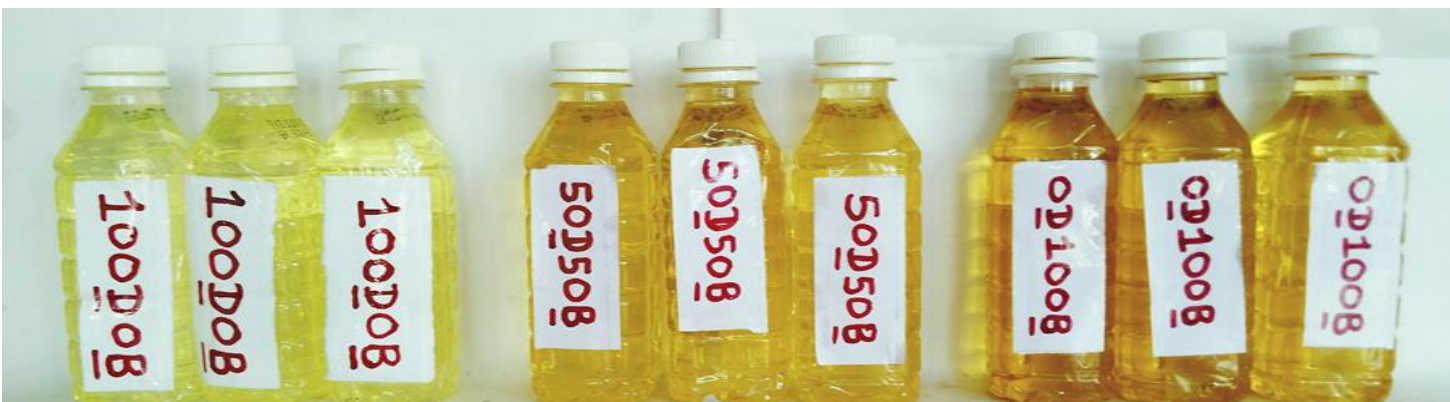

Fig 4.2.2 Diesel, Blended Fuel \&Jatropha bio oil

\section{Result \& Discussion}

At the end of the experiment final data collected easily by the ICEngine soft. Directly. Observation table \& graph of emission analysis is as discussed below.

\subsection{Engine performance data using engine normal condition:}

The result data obtained from the observed data for the engine running at normal condition is given in table. In this table exp. 1 to 9 used pure diesel (D100B0), exp. 10 to 18 used blendeddiesel (D50B50) \& exp. 19 to 27 used Jatropha biodiesel (D0B100) as an engine fuel.

Table 5.1 Different blends performance data with normal condition of engine

\begin{tabular}{|c|c|c|c|c|c|c|c|c|c|c|c|}
\hline $\begin{array}{l}\text { Ex } \\
\text { no. }\end{array}$ & 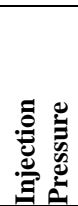 & 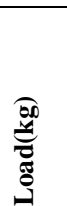 & 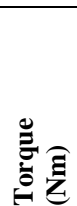 & $\sum_{3}^{\infty}$ & $\sum_{y}^{x}$ & $\sum_{y}^{x}$ & 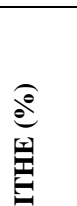 & 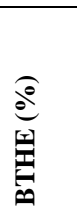 & 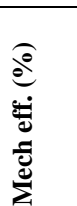 & $\underset{\frac{0}{0}}{\frac{8}{0}}$ & 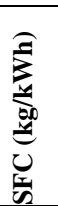 \\
\hline 1 & $\mathrm{~L}$ & 1.02 & 1.86 & 3.68 & 0.3 & 3.68 & 88.28 & 6.62 & 7.5 & 69.57 & 1.41 \\
\hline 2 & $\mathrm{~L}$ & 5.02 & 9.11 & 5.19 & 1.44 & 3.74 & 72.69 & 20.24 & 27.84 & 69.34 & 0.42 \\
\hline 3 & $\mathrm{~L}$ & 8.89 & 16.13 & 6.22 & 2.51 & 3.71 & 65.39 & 26.37 & 40.33 & 69.19 & 0.32 \\
\hline 4 & M & 1.02 & 1.85 & 4.04 & 0.3 & 3.74 & 84.87 & 6.24 & 7.35 & 69.72 & 1.35 \\
\hline 5 & $\mathrm{M}$ & 5.01 & 9.09 & 5.06 & 1.44 & 3.62 & 70.87 & 20.13 & 28.41 & 69.32 & 0.42 \\
\hline 6 & $M$ & 8.98 & 16.3 & 6.19 & 2.51 & 3.67 & 61.16 & 24.84 & 40.61 & 68.98 & 0.34 \\
\hline 7 & $\mathrm{H}$ & 1 & 1.82 & 3.85 & 0.29 & 3.55 & 80.8 & 6.12 & 7.58 & 69.69 & 1.37 \\
\hline 8 & $\mathrm{H}$ & 4.92 & 8.92 & 4.98 & 1.38 & 3.59 & 69.7 & 19.35 & 27.76 & 69.62 & 0.43 \\
\hline 9 & $\mathrm{H}$ & 8.97 & 16.27 & 6.23 & 2.52 & 3.72 & 65.47 & 26.42 & 40.36 & 68.85 & 0.32 \\
\hline 10 & $\mathrm{~L}$ & 0.99 & 1.79 & 4.02 & 0.29 & 3.73 & 75.15 & 5.43 & 7.23 & 69.6 & 1.55 \\
\hline 11 & $\mathrm{~L}$ & 5.01 & 9.1 & 5.08 & 1.44 & 3.64 & 67.47 & 19.18 & 28.42 & 69.1 & 0.46 \\
\hline 12 & $\mathrm{~L}$ & 8.79 & 15.94 & 6.52 & 2.45 & 4.07 & 66.14 & 24.85 & 37.57 & 69.02 & 0.36 \\
\hline 13 & M & 0.98 & 1.79 & 4.1 & 0.29 & 3.81 & 78.55 & 5.55 & 7.07 & 69.4 & 1.6 \\
\hline 14 & M & 4.99 & 9.05 & 5.22 & 1.43 & 3.79 & 69.24 & 18.98 & 27.41 & 69.16 & 0.47 \\
\hline 15 & M & 8.33 & 16.03 & 6.36 & 2.43 & 3.93 & 64.54 & 24.64 & 38.19 & 69.1 & 0.36 \\
\hline 16 & $\mathrm{H}$ & 0.97 & 1.76 & 3.93 & 0.28 & 3.65 & 75.28 & 5.32 & 7.07 & 69.68 & 1.67 \\
\hline 17 & $\mathrm{H}$ & 4.96 & 9 & 5.25 & 1.42 & 3.83 & 75.52 & 20.38 & 26.99 & 69.12 & 0.43 \\
\hline 18 & $\mathrm{H}$ & 8.86 & 16.07 & 6.65 & 2.46 & 4.19 & 67.5 & 24.93 & 36.93 & 69.08 & 0.36 \\
\hline 19 & $\mathrm{~L}$ & 0.95 & 1.72 & 4.26 & 0.27 & 3.99 & 81.72 & 5.26 & 6.44 & 69.06 & 1.68 \\
\hline 20 & $\mathrm{~L}$ & 5.07 & 9.2 & 5.87 & 1.46 & 4.41 & 80.07 & 19.97 & 24.94 & 69.2 & 0.47 \\
\hline 21 & $\mathrm{~L}$ & 8.95 & 16.25 & 6.84 & 2.53 & 4.31 & 67.39 & 24.91 & 36.96 & 68.88 & 0.38 \\
\hline 22 & $M$ & 0.97 & 1.75 & 4.37 & 0.28 & 4.09 & 86.17 & 5.56 & 6.45 & 69.51 & 1.68 \\
\hline 23 & M & 5.01 & 9.09 & 5.59 & 1.42 & 4.17 & 76.28 & 19.34 & 25.35 & 69.5 & 0.48 \\
\hline 24 & M & 8.86 & 16.07 & 6.53 & 2.48 & 4.06 & 68.15 & 25.82 & 37.89 & 68.76 & 0.36 \\
\hline 25 & $\mathrm{H}$ & 0.96 & 1.73 & 4.18 & 0.27 & 3.91 & 82.34 & 5.37 & 6.52 & 69.8 & 1.74 \\
\hline 26 & $\mathrm{H}$ & 5 & 9.08 & 5.55 & 1.42 & 4.14 & 75.71 & 19.32 & 25.51 & 69.28 & 0.48 \\
\hline 27 & $\mathrm{H}$ & 8.78 & 15.93 & 6.48 & 2.43 & 4.05 & 71.8 & 26.91 & 37.47 & 69 & 0.35 \\
\hline
\end{tabular}

\subsection{Engine performance data using engine supercharging condition}

The result data obtained from the observed data for the engine running at supercharging condition is given in table. In this table exp. 1 to 9 used pure diesel (D100B0), exp. 10 to 18 used blended diesel (D50B50) \& exp. 19 to 27 used Jatropha biodiesel (D0B100) as an engine fuel. 
Table 5.2 Different blends performance data with engine supercharging condition

\begin{tabular}{|c|c|c|c|c|c|c|c|c|c|c|c|}
\hline Ex no. & 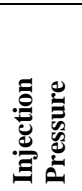 & 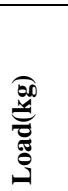 & 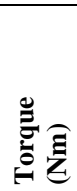 & $\sum_{\theta}^{E}$ & 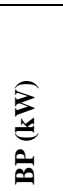 & 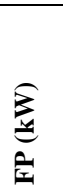 & $\underbrace{2}$ & 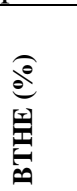 & 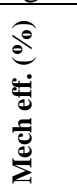 & $\underset{\frac{0}{0}}{\stackrel{0}{0}}$ & 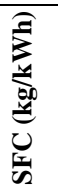 \\
\hline 1 & $\mathrm{~L}$ & 1.1 & 1.99 & 4.42 & 0.32 & 4.1 & 90.64 & 6.64 & 7.31 & 141.03 & 1.23 \\
\hline 2 & $\mathrm{~L}$ & 5.08 & 9.23 & 5.94 & 1.47 & 4.46 & 76.74 & 19.07 & 24.85 & 147.18 & 0.44 \\
\hline 3 & $\mathrm{~L}$ & 9.07 & 16.46 & 6.7 & 2.56 & 4.14 & 66.28 & 25.34 & 38.24 & 151.03 & 0.33 \\
\hline 4 & $\mathrm{M}$ & 1.15 & 2.08 & 4.97 & 0.35 & 4.62 & 83.53 & 5.83 & 6.98 & 141.07 & 1.44 \\
\hline 5 & $\mathrm{M}$ & 5.01 & 9.1 & 5.68 & 1.43 & 4.25 & 73.43 & 18.51 & 25.21 & 149.43 & 0.45 \\
\hline 6 & $\mathrm{M}$ & 8.99 & 16.32 & 6.53 & 2.52 & 4.02 & 68.64 & 26.43 & 38.51 & 152.57 & 0.32 \\
\hline 7 & $\mathrm{H}$ & 1.12 & 2.03 & 4.82 & 0.33 & 4.49 & 90.03 & 6.14 & 6.81 & 145.28 & 1.37 \\
\hline 8 & $\mathrm{H}$ & 5.02 & 9.11 & 5.66 & 1.42 & 4.23 & 79.22 & 19.94 & 25.17 & 150.52 & 0.42 \\
\hline 9 & $\mathrm{H}$ & 8.92 & 16.19 & 6.49 & 2.49 & 4 & 68.16 & 26.11 & 38.31 & 153.2 & 0.32 \\
\hline 10 & $\mathrm{~L}$ & 0.94 & 1.71 & 4.23 & 0.27 & 3.96 & 88.82 & 5.71 & 6.43 & 147.85 & 1.47 \\
\hline 11 & $\mathrm{~L}$ & 4.98 & 9.04 & 5.17 & 1.44 & 3.73 & 74.42 & 20.72 & 27.84 & 147.56 & 0.43 \\
\hline 12 & $\mathrm{~L}$ & 9.08 & 16.48 & 6.13 & 2.54 & 3.59 & 62.25 & 25.79 & 41.43 & 152.57 & 0.34 \\
\hline 13 & $\mathrm{M}$ & 0.96 & 1.75 & 4.31 & 0.28 & 4.03 & 92.92 & 6.09 & 6.55 & 145.84 & 1.46 \\
\hline 14 & $\mathrm{M}$ & 4.97 & 9.02 & 5.21 & 1.44 & 3.77 & 74.87 & 20.7 & 27.64 & 147.46 & 0.43 \\
\hline 15 & $\mathrm{M}$ & 9.07 & 16.46 & 6.36 & 2.53 & 3.83 & 64.58 & 25.65 & 39.72 & 153.2 & 0.35 \\
\hline 16 & $\mathrm{H}$ & 0.95 & 1.72 & 4.46 & 0.28 & 4.18 & 96.19 & 5.27 & 6.19 & 146.4 & 1.49 \\
\hline 17 & $\mathrm{H}$ & 4.9 & 8.9 & 5.14 & 1.38 & 3.75 & 73.88 & 19.91 & 26.96 & 151.14 & 0.45 \\
\hline 18 & $\mathrm{H}$ & 9.01 & 16.36 & 6.22 & 2.52 & 3.7 & 63.11 & 25.59 & 40.56 & 152.56 & 0.35 \\
\hline 19 & $\mathrm{~L}$ & 0.98 & 1.79 & 4.53 & 0.29 & 4.24 & 97.73 & 6.21 & 6.35 & 146.12 & 1.43 \\
\hline 20 & $\mathrm{~L}$ & 4.91 & 8.92 & 5.4 & 1.4 & 4 & 79.81 & 20.73 & 25.97 & 149.53 & 0.45 \\
\hline 21 & $\mathrm{~L}$ & 8.99 & 16.32 & 6.63 & 2.52 & 4.11 & 69.13 & 26.31 & 38.06 & 152.16 & 0.36 \\
\hline 22 & $\mathrm{M}$ & 0.99 & 1.8 & 4.77 & 0.3 & 4.48 & 105.75 & 6.56 & 6.2 & 142.96 & 1.43 \\
\hline 23 & $\mathrm{M}$ & 4.88 & 8.85 & 5.41 & 1.38 & 4.03 & 79.96 & 20.42 & 25.54 & 150.63 & 0.46 \\
\hline 24 & $\mathrm{M}$ & 9.02 & 16.37 & 6.9 & 2.55 & 4.35 & 71.94 & 26.62 & 37 & 150.82 & 0.35 \\
\hline 25 & $\mathrm{H}$ & 0.99 & 1.8 & 4.77 & 0.29 & 4.47 & 93.93 & 5.79 & 6.16 & 143.96 & 1.62 \\
\hline 26 & $\mathrm{H}$ & 4.92 & 8.94 & 5.63 & 1.42 & 4.21 & 83.23 & 20.98 & 25.21 & 148.04 & 0.45 \\
\hline 27 & $\mathrm{H}$ & 8.96 & 16.27 & 6.5 & 2.51 & 3.99 & 67.77 & 26.15 & 38.59 & 152.57 & 0.36 \\
\hline
\end{tabular}

An alternative fuel used in engines is always evaluated on the basis of both engine performances and its environmental impacts. As such, various parameters defining the performance and emissions of diesel engine which have been evaluated both experimentally and numerically in this work and have been discussed and analyzed in this section.Energy sources being considered diesel, biodiesel for the purpose of present work. After the engine reached the stabilized working condition fuel consumption, air consumption, engine load and exhaust emissions were measured. Engine power for diesel was $5.2 \mathrm{~kW}$ when engine speed was at $1500 \mathrm{rpm}$.In this section, the simulated results are verified with experimental results at the same operating conditions. The validation is done with three extreme fuels, namely pure Jatropha biodiesel (D0B100) Blended Jatropha biodiesel (D50B50) and mineral Diesel (D100B0). In this paper mainly performance parameters are considered at different injection pressure and different load condition with different blends.

This paper included the comparative analysis of various experimental data for various test conditions. An alternative fuel used in engines is always evaluated on the basis of both engine performances and its environmental impacts. As such, various parameters defining the performance characteristics of diesel engine which have been evaluated graphically in this work and have been discussed and analyzed in this section.

\subsection{Specific Fuel Consumption}

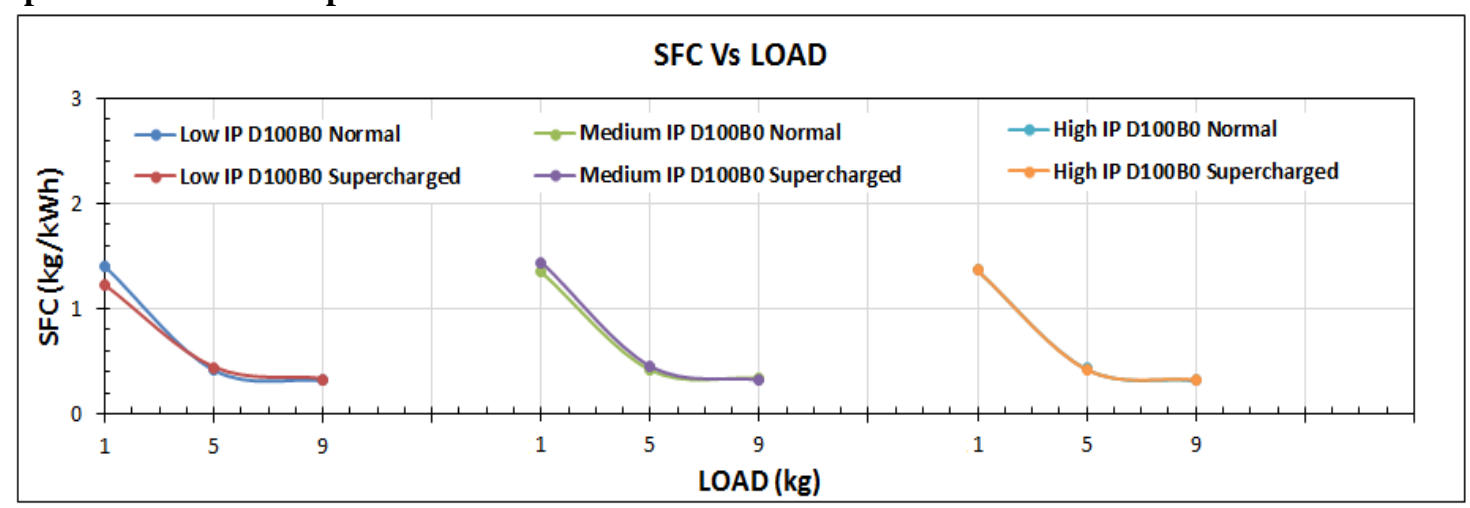

Fig 5.3.1 Specific fuel consumption Vs Load of D100B0 


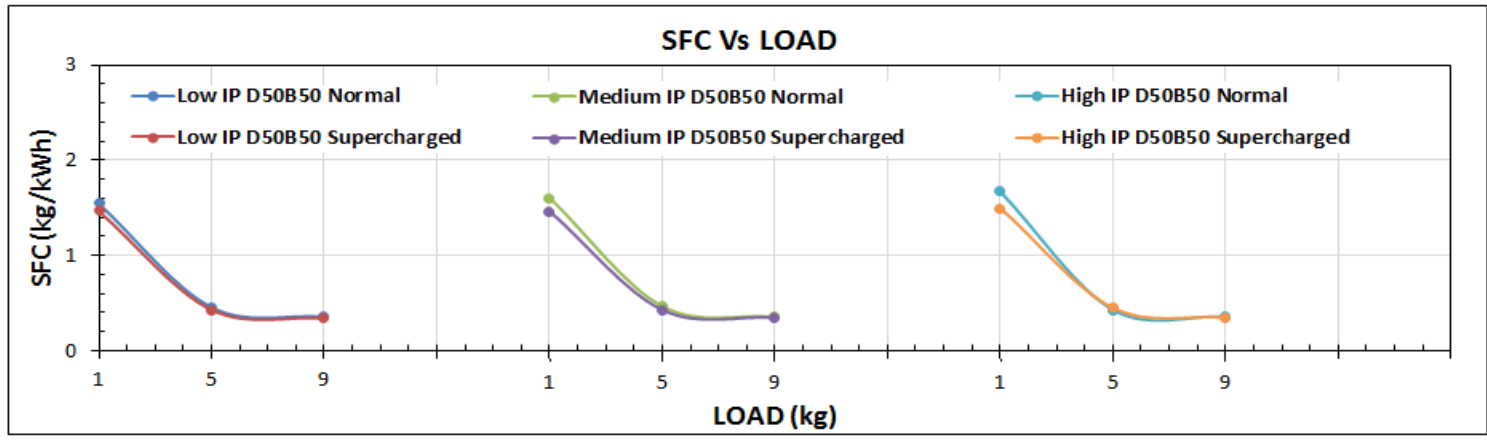

Fig 5.3.2 Specific fuel consumption Vs Load of D50B50

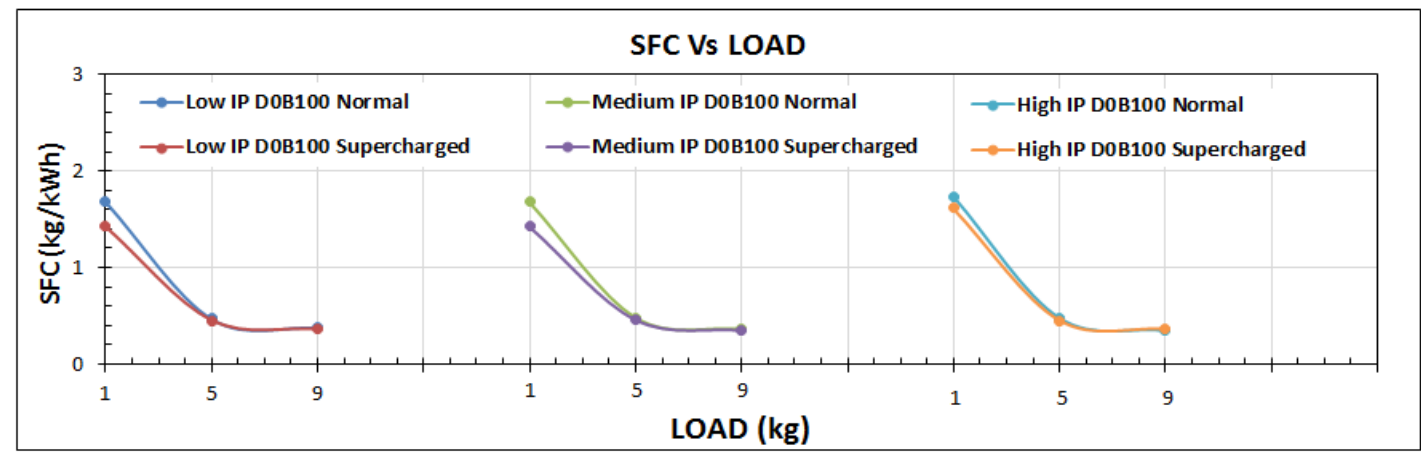

Fig 5.3.3 Specific fuel consumption Vs Load of D0B100

The specific fuel consumption depends upon the engine power. The specific fuel consumption decreases with increase in load. By added the Jatropha biodiesel at the various proportions of $0 \%, 50 \%$ \& $100 \%$.Specific fuel consumption considerably increased for all load conditions. It means as the concentration of Jatropha biodiesel increased the SFC also increased. But from the above graph it shows that the SFC is best in the D0B100 blend which is optimum compare to other blend.

- For D100B0 minimum SFC is $0.32 \mathrm{Kg} / \mathrm{kWh}$ at load $9 \mathrm{~kg} \&$ low and high injection pressure condition of engine normal condition. For D100B0 maximum SFC is $0.32 \mathrm{Kg} / \mathrm{kWh}$ at load $9 \mathrm{~kg} \&$ medium injection pressure \& high injection pressure condition of engine supercharging condition.

- For D50B50 minimum $\mathrm{SFC}$ is $0.36 \mathrm{Kg} / \mathrm{kWh}$ at load $9 \mathrm{~kg} \&$ low, medium and high injection pressure condition of engine normal condition. For D100B0 maximum SFC is $0.34 \mathrm{Kg} / \mathrm{kWh}$ at load $9 \mathrm{~kg} \&$ low injection pressure condition of engine supercharging condition.

- For D100B0 minimum SFC is $0.35 \mathrm{Kg} / \mathrm{kWh}$ at load $9 \mathrm{~kg} \&$ high injection pressure condition of engine normal condition. For D100B0 maximum SFC is $0.35 \mathrm{Kg} / \mathrm{kWh}$ at load $5 \mathrm{~kg} \&$ medium injection pressure condition of engine supercharging condition.

- So optimum specific fuel consumption were obtained for to be $0.34 \mathrm{Kg} / \mathrm{kWh}$ for D0B100 when engine run at supercharged condition compared to diesel.

\subsection{Fuel Consumption}

The variations of fuel consumption with load under various blends are shown in figure.

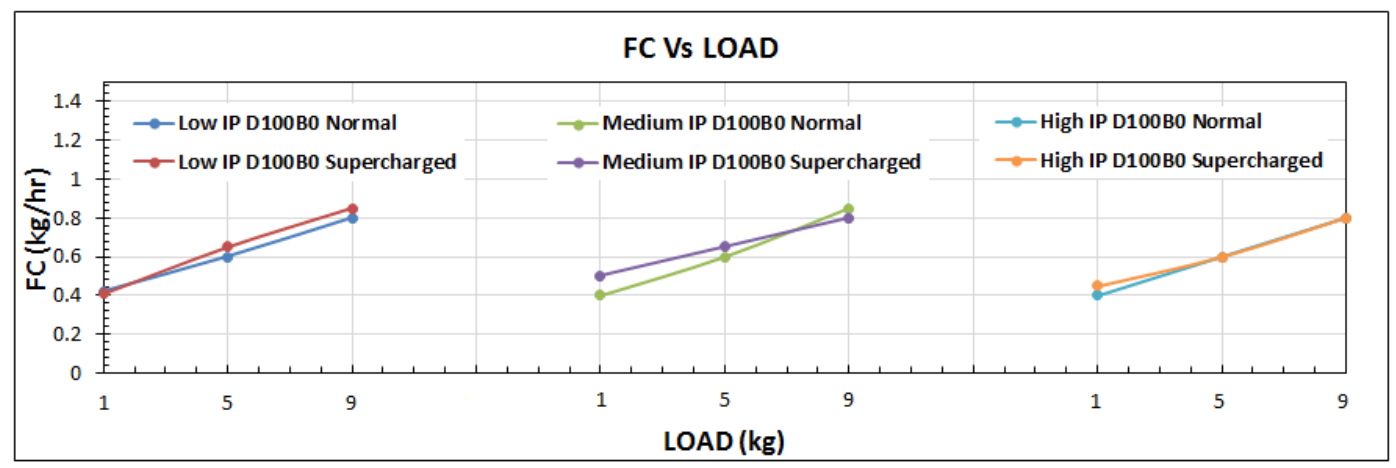

Fig 5.4.1 Fuel consumption Vs Load of D100B0 


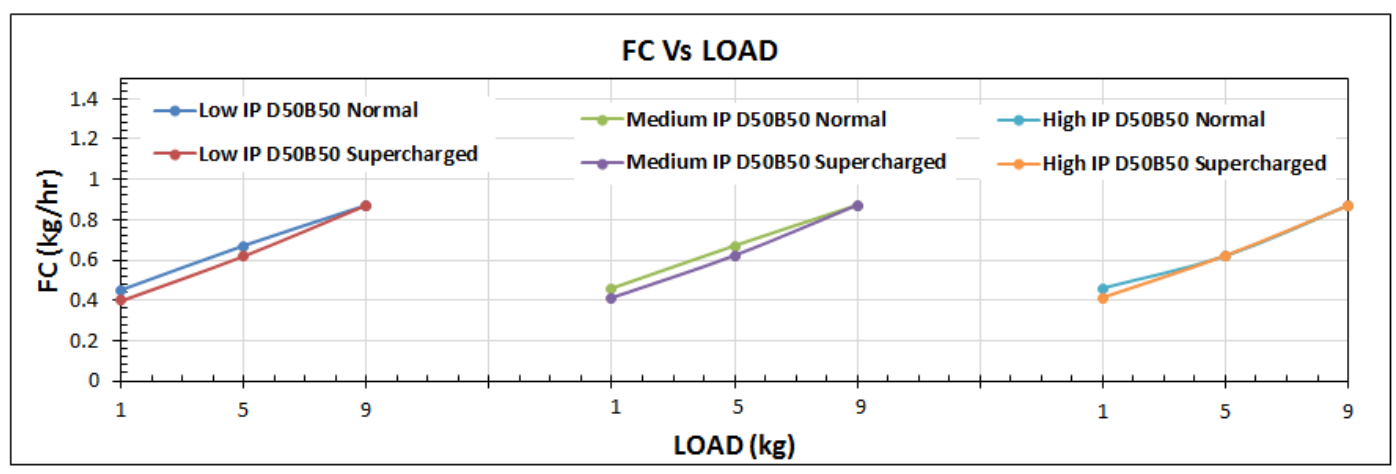

Fig 5.4.2 Fuel consumption Vs Load of D50B50

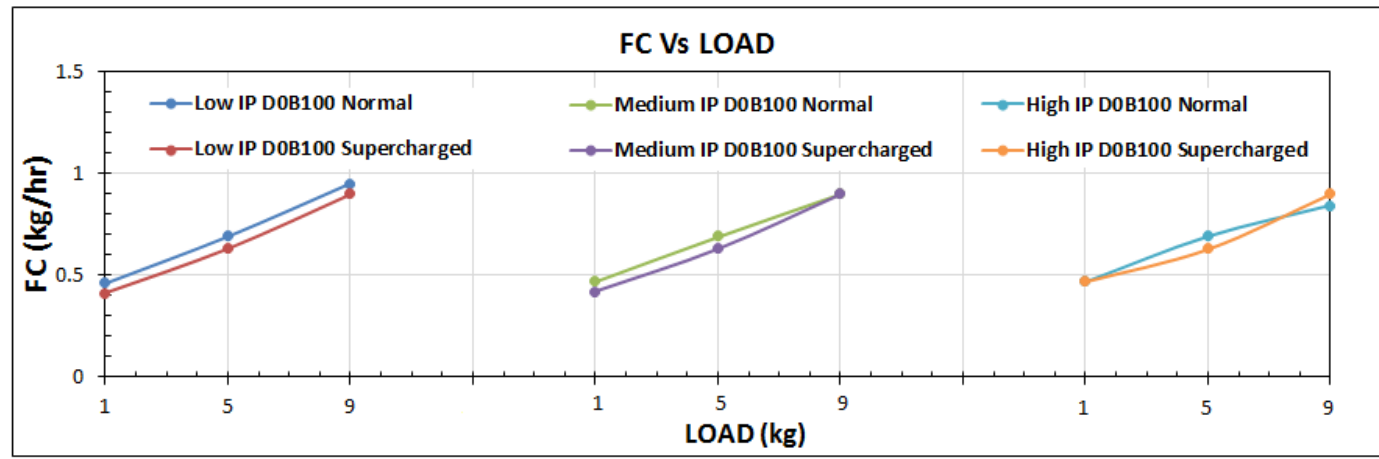

Fig 5.4.3 Fuel consumption Vs Load of D0B100

From the graph it is concluded that the fuel consumption of the blended fuel is same as conventional diesel fuel. It also shows that as the load increased the fuel consumption also increased. In pure diesel engine running at supercharging condition there is little more consumption of fuel compared to normal condition of diesel engine. While in blended Jatropha fuel \& pure Jatropha bio oil there is vice versa.

- For D100B0 minimum fuel consumption is $0.4 \mathrm{~kg} / \mathrm{hr}$. at load $1 \mathrm{~kg} \&$ high injection pressure condition of engine normal condition. For D100B0 minimum fuel consumption is $0.41 \mathrm{~kg} / \mathrm{hr}$. at load $1 \mathrm{~kg} \&$ low injection pressure condition of engine supercharging condition.

- For D50B50 minimum fuel consumption is $0.45 \mathrm{~kg} / \mathrm{hr}$. at load $1 \mathrm{~kg} \&$ low injection pressure condition of engine normal condition. For D50B50 minimum fuel consumption is $0.40 \mathrm{~kg} / \mathrm{hr}$. at load $1 \mathrm{~kg} \&$ low injection pressure condition of engine supercharging condition.

- For D0B100 minimum fuel consumption is $0.46 \mathrm{~kg} / \mathrm{hr}$. at load $1 \mathrm{~kg} \&$ low injection pressure condition of engine normal condition. For D0B100 minimum fuel consumption is $0.41 \mathrm{~kg} / \mathrm{hr}$. at load $1 \mathrm{~kg} \&$ low injection pressure condition of engine supercharging condition.

- So optimum fuel consumption were obtained for to be $0.40 \%$ for D50B50 \& $0.41 \%$ for D0B 100 when engine run at supercharged condition compared to diesel.

\subsection{Air Fuel Ratio}

The variations of air fuel ratio with load under various blends \& under various condition of engine are shown in figure.

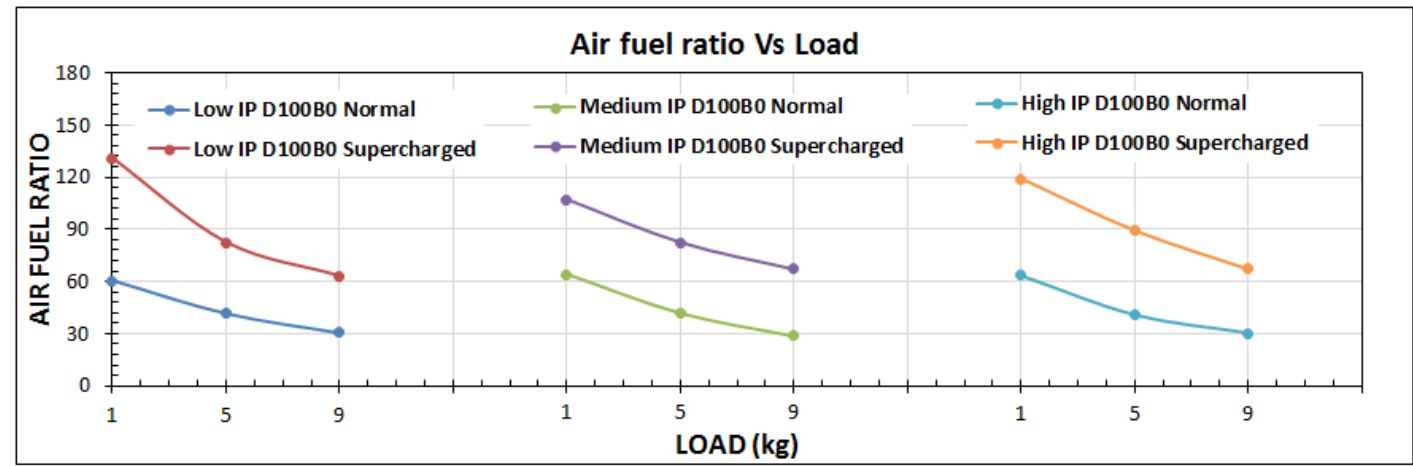

Fig 5.5.1 Air fuel ratio Vs Load of D100B0 


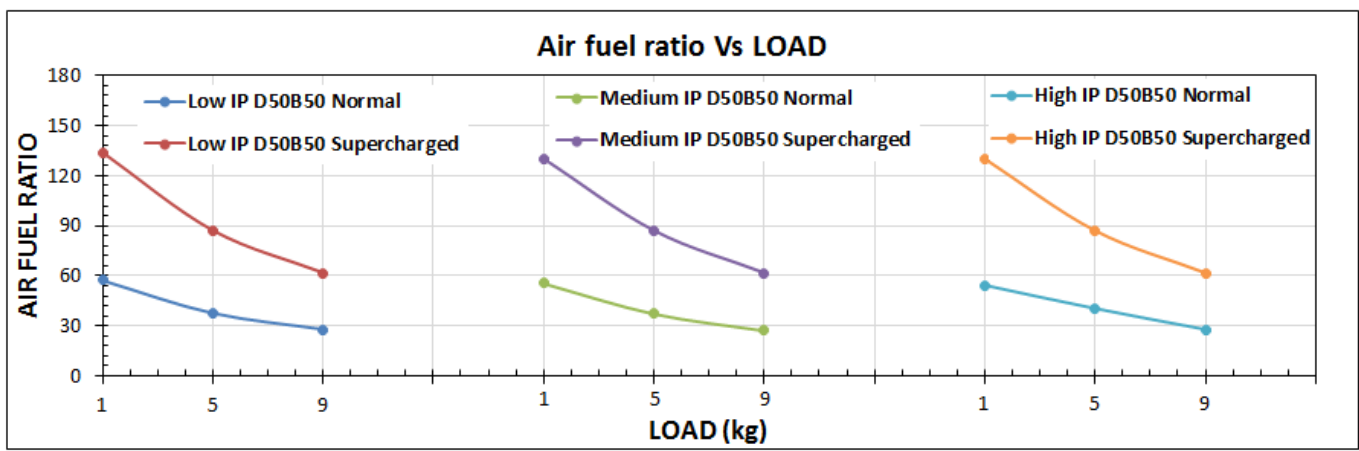

Fig 5.5.2 Air fuel ratio Vs Load of D50B50

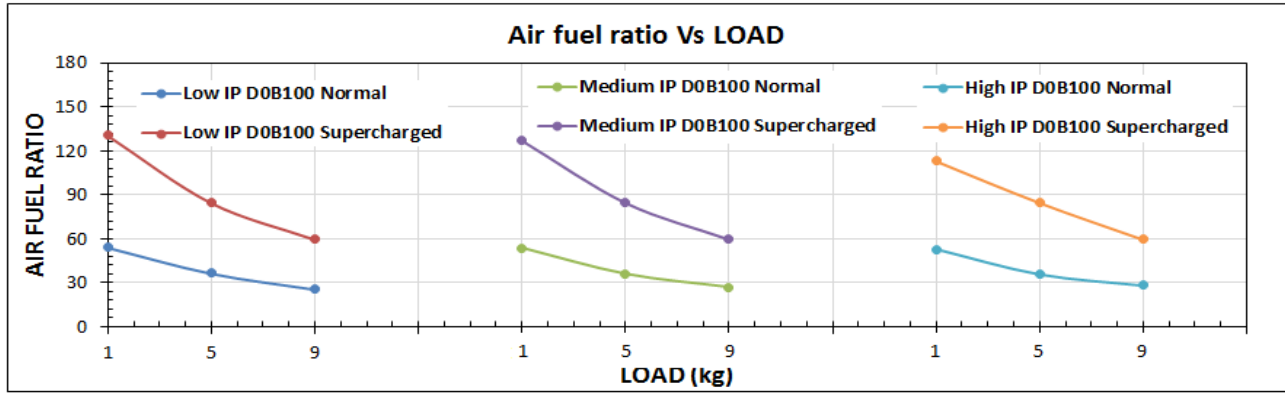

Fig 5.5.3 Air fuel ratio Vs Load of D0B100

Air-fuel ratio is the mass ratio of air to fuel present in a combustion process. Which is directly affect the performance of the engine. If the air fuel ratio increased so which burn a greater amount of fuel in a given engine. With the use of air compressor we change the inlet air supply \& take reading \& conclude what effect of supercharging of air inlet in diesel engine. As shown in graph as load increased which effect the air fuel ratio is decreased.

\subsection{Indicated Thermal Efficiency}

The variations of indicated thermal efficiency with different load under various blends \& under various condition of engine are shown in figure.

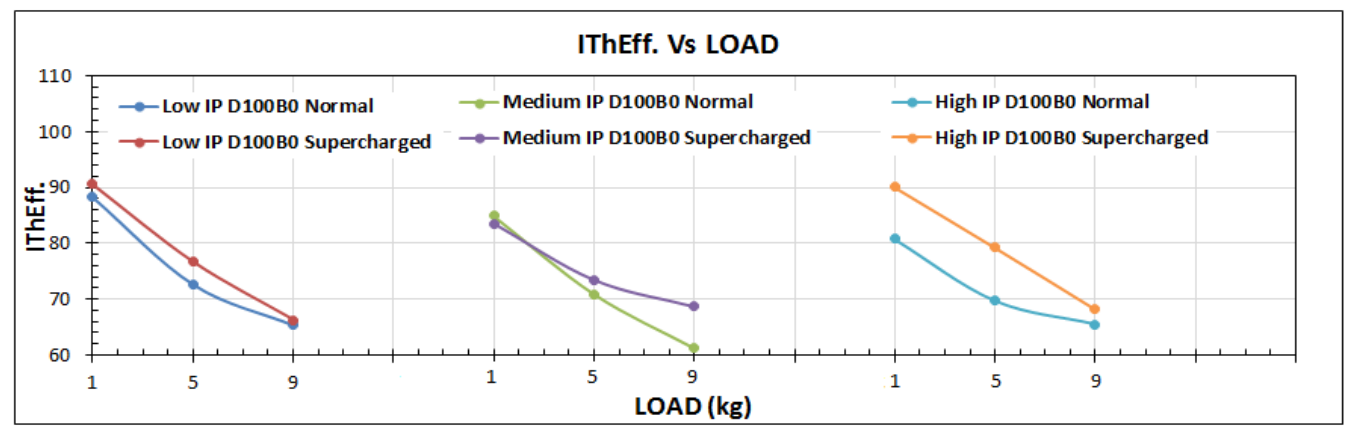

Fig 5.6.1 Indicated Thermal Efficiency Vs Load of D100B0

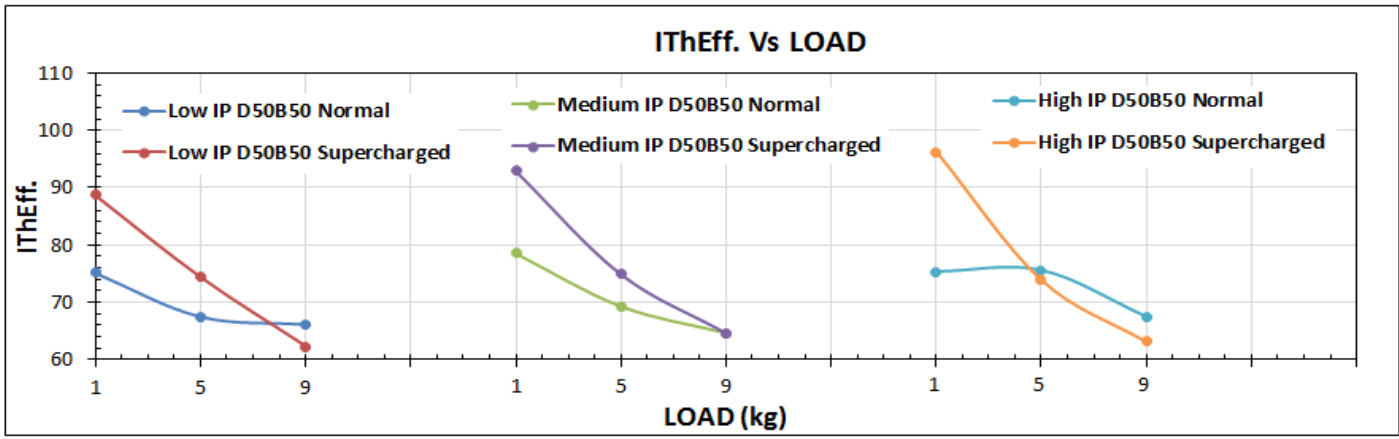

Fig 5.6.2 Indicated Thermal Efficiency Vs Load of D50B50 


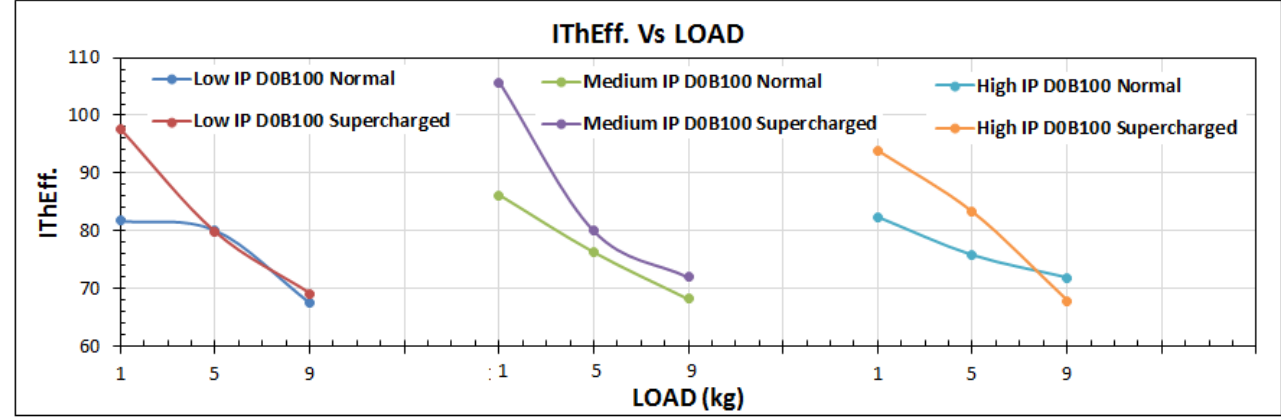

Fig 5.6.3 Indicated Thermal Efficiency Vs Load of D0B100

The ratio between the indicated power output of an engine and the rate of supply of energy in the fuel. Thermal efficiency indicates the extent to which the energy added by fuel is converted to total work output. From the graph it is concluded that as the load increased the thermal efficiency is decreased. In pure diesel engine running at supercharging condition there is only in high injection pressure there is great difference of thermal efficiency compared to normal condition of diesel engine. While in blended Jatropha fuel \& pure Jatropha bio oil there is big difference in thermal efficiency in supercharging condition compared to normal condition of engine at low load.

- For D100B0 Indicated thermal efficiency is $65.47 \%$ at load $9 \mathrm{~kg} \&$ high injection pressure condition of engine normal condition. For D100B0 maximum Brake thermal efficiency is $68.16 \%$ at load $9 \mathrm{~kg} \& \mathrm{high}$ injection pressure condition of engine supercharging condition.

- For D50B50 Indicated thermal efficiency is $67.50 \%$ at load $9 \mathrm{~kg} \&$ high injection pressure condition of engine normal condition. For D100B0 maximum Brake thermal efficiency is $63.11 \%$ at load $9 \mathrm{~kg} \& \mathrm{high}$ injection pressure condition of engine supercharging condition.

- For D0B100 Indicated thermal efficiency is $71.80 \%$ at load $9 \mathrm{~kg} \&$ high injection pressure condition of engine normal condition. For D100B0 maximum Brake thermal efficiency is $67.77 \%$ at load $9 \mathrm{~kg} \& \mathrm{high}$ injection pressure condition of engine supercharging condition.

- Maximum thermal efficiency were obtained with use of D0B100 fuel at medium injection pressure at low load as $86.17 \%$ in normal engine condition \& in supercharging condition with use of D0B100 fuel efficiency is $105.75 \%$ at medium injection pressure at low load.

- So maximum indicated thermal efficiencies were obtained for to be $71.80 \%$ for D0B100 when engine run at normal condition compared to diesel.

\subsection{Brake Thermal Efficiency}

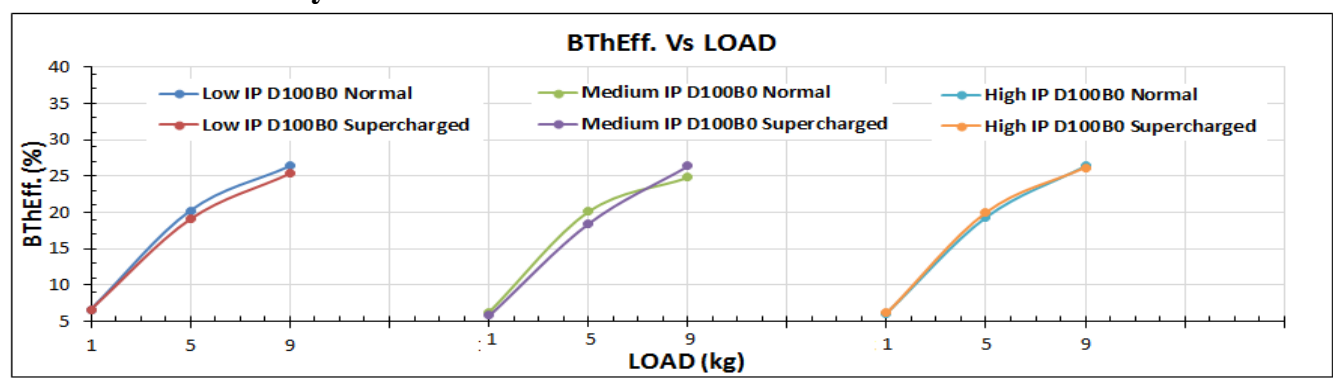

Fig 5.7.1 Brake Thermal Efficiency Vs Load of D100B0

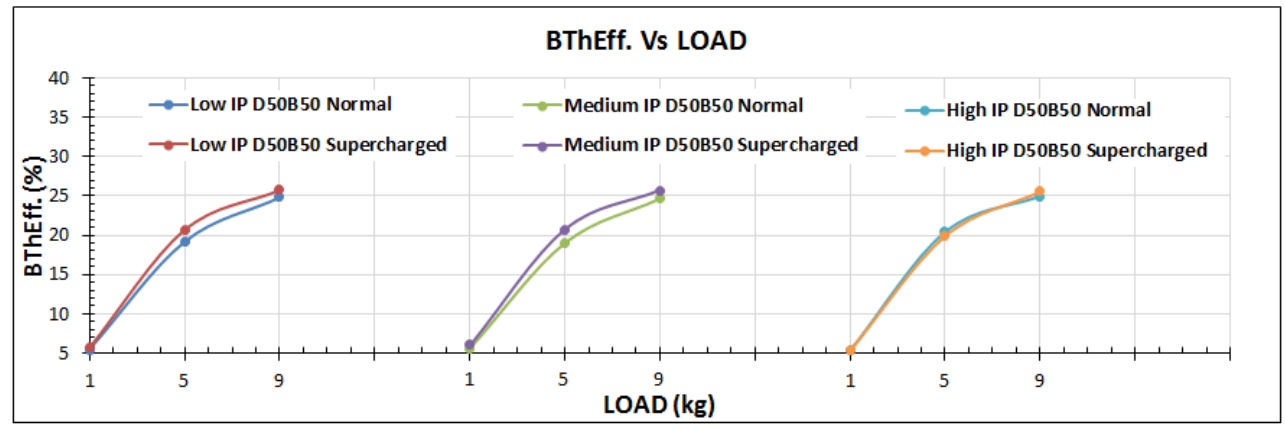

Fig 5.7.2 Brake Thermal Efficiency Vs Load of D50B50 


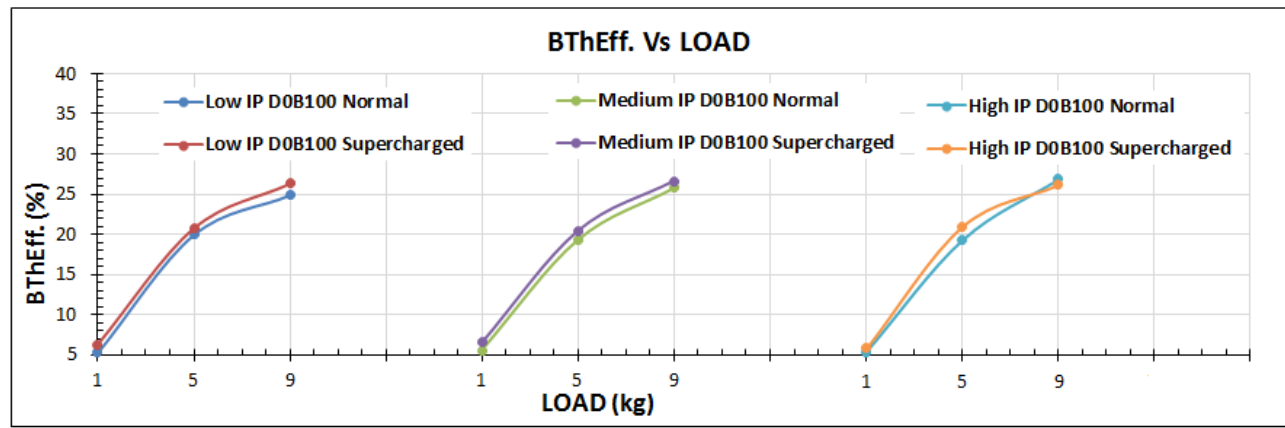

Fig 5.7.3Brake Thermal Efficiency Vs Load of D0B100

Brake thermal efficiency is one of the most important engine performance parameter which indicates the percentage of fuel energy converted to useful power output. Brake thermal efficiency is defined as the ratio of brake power to product of fuel consumption and calorific value.

Figure represents the variation of brake thermal efficiency of diesel at different load on low, medium \& high injection pressure of the engine running at normal \& supercharging condition for different fuel. Above graph shows that the brake thermal efficiency increased with increased in the load. From figure concluded that the Brake thermal efficiency of diesel is same for low, medium \& high injection pressure.

- For D100B0 maximum Brake thermal efficiency is $26.42 \%$ at load $9 \mathrm{~kg} \&$ high injection pressure condition of engine normal condition. For D100B0 maximum Brake thermal efficiency is $26.43 \%$ at load $9 \mathrm{~kg} \&$ medium injection pressure condition of engine supercharging condition.

- For D50B50 maximum Brake thermal efficiency is $24.93 \%$ at load $9 \mathrm{~kg} \&$ high injection pressure condition of engine normal condition. For D50B50 maximum Brake thermal efficiency is $25.79 \%$ at load $9 \mathrm{~kg} \&$ low injection pressure condition of engine supercharging condition.

- For D0B100 maximum Brake thermal efficiency is $26.91 \%$ at load $9 \mathrm{~kg} \&$ high injection pressure condition of engine normal condition. For D0B1000 maximum Brake thermal efficiency is $26.62 \%$ at load $9 \mathrm{~kg} \mathrm{\&}$ medium injection pressure condition of engine supercharging condition.

- So maximum brake thermal efficiencies were obtained for to be $26.91 \%$ for D0B 100 when engine run at normal condition compared to diesel.

\subsection{Mechanical Efficiency}

The variations of mechanical efficiency with load under various blends \& under various condition of engine are shown in figure. Mechanical efficiency is defined as the ratio of power available on the shaft to the power developed in the engine means it is a ratio of brake power to the indicated power.

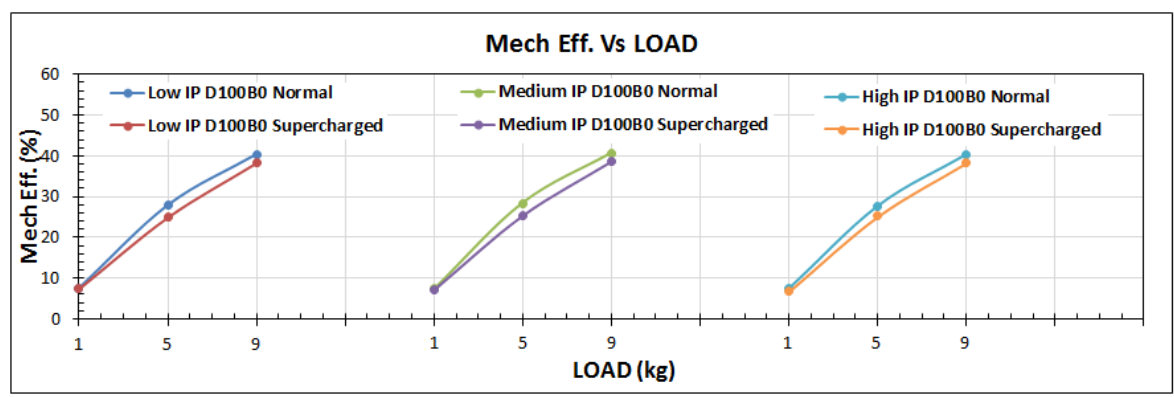

Fig 5.8.1 Mechanical Efficiency Vs Load of D100B0

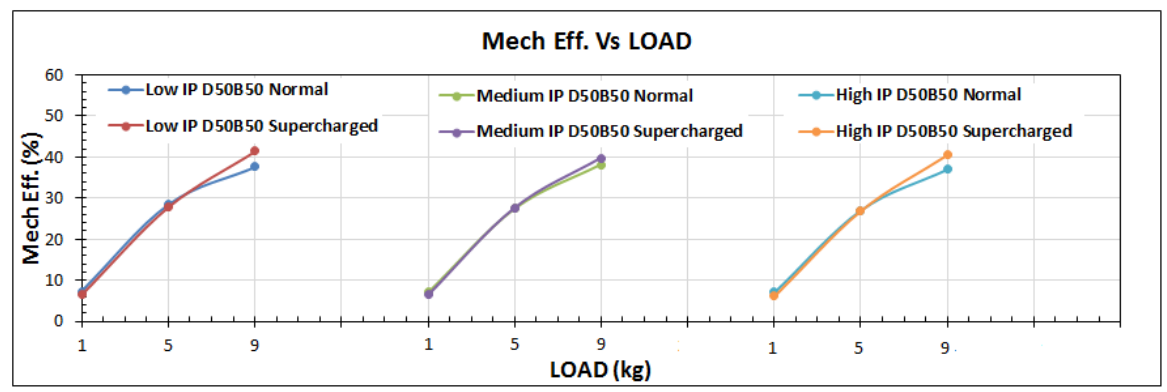

Fig 5.8.2 Mechanical Efficiency Vs Load of D50B50 


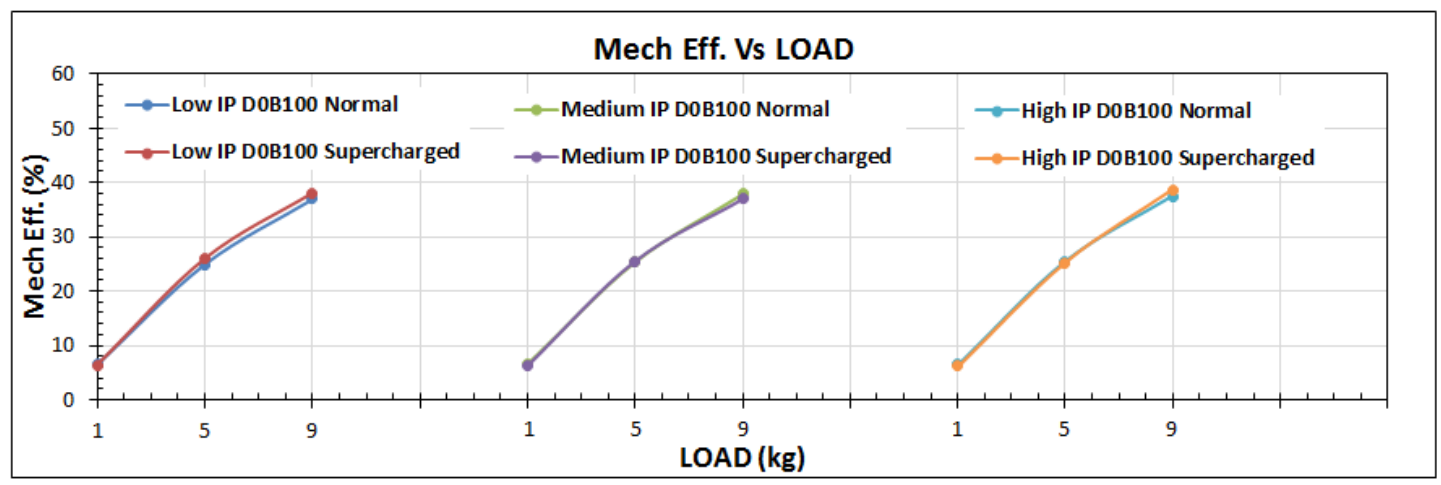

Fig 5.8.3 Mechanical Efficiency Vs Load of D0B100

From fig it is concluded that the mechanical efficiency increases with increase in load. From fig it is concluded that the mechanical efficiencies of all blends are very similar to diesel in engine normal condition but in supercharged condition there is difference.

- For D100B0 Mechanical efficiency is $40.36 \%$ at load $9 \mathrm{~kg} \&$ high injection pressure condition of engine normal condition. For D100B0 maximum Mechanical efficiency is $38.31 \%$ at load $9 \mathrm{~kg} \&$ high injection pressure condition of engine supercharging condition.

- For D50B50 Mechanical efficiency is $36.93 \%$ at load $9 \mathrm{~kg} \&$ high injection pressure condition of engine normal condition. For D100B0 maximum Mechanical efficiency is $40.56 \%$ at load $9 \mathrm{~kg} \&$ high injection pressure condition of engine supercharging condition.

- For D0B100 Mechanical efficiency is $37.47 \%$ at load $9 \mathrm{~kg} \&$ high injection pressure condition of engine normal condition. For D100B0 maximum Mechanical efficiency is $38.59 \%$ at load $9 \mathrm{~kg} \&$ high injection pressure condition of engine supercharging condition.

- Maximum Mechanical efficiency were obtained with the use of D50B50 fuel at medium injection pressure at $9 \mathrm{~kg}$ load as $38.19 \%$ in normal engine condition \& in supercharging condition with use of D50B50 fuel efficiency is $41.43 \%$ at low injection pressure at $9 \mathrm{~kg}$ load.

- So maximum Mechanical efficiencies were obtained for to be $38.59 \%$ for D0B100 when engine run at normal condition compared to diesel.

\section{Conclusion}

From the engine performance characteristic was studied, it can be concluded that

- The fuel consumption of all blends are slightly more than the diesel at all varying loads. But D50B50 Jatropha biodiesel blend have considerable lesser fuel consumption at low \& medium injection pressure than all among blends and diesel at engine supercharging conditions.

- Optimum specific fuel consumption were obtained for D0B100 when engine run at supercharged condition compared to diesel, which is nearest to the diesel fuel.

- The brake thermal efficiency of D0B100 Jatropha biodiesel blend is more among all other blends at all loads which is slightly greater than the diesel fuel.

- The mechanical efficiency of all blends are less than diesel fuel. It is concluded that the D50B50 blend have highest mechanical efficiency at engine supercharging condition is $41.43 \%$ at low injection pressure at higher load than all among blends as well as diesel.

- The use of Jatropha biodiesel in a conventional diesel engine decreases its torque and brake thermal efficiency, the decrease being more with increase in the biodiesel blends.

\section{References}

[1] Berchmans, H. J., \& Hirata, S. (2008). Biodiesel production from crude Jatrophacurcas L. seed oil with a high content of free fatty acids. Bioresource Technology, 99(6), 1716-1721. https://doi.org/10.1016/j.biortech.2007.03.051

[2] Hanumantha Rao, Y. V., Voleti, R. S., Sitarama Raju, A. V., \&Nageswara Reddy, P. (2009). Experimental investigations on Jatropha biodiesel and additive in diesel engine. Indian Journal of Science and Technology, 2(4), 25-31. https://doi.org/10.17485/ijst/2009/v2i4/29426

[3] Jindal, S. (2011). Effect of injection timing on combustion and performance of a direct injection diesel engine running on Jatropha methyl ester. International Journal of Energy and Environment, 2(1), 113-122

[4] Kim, J., Yim, E., Jeon, C., Jung, C., \& Han, B. (2012). Cold performance of various biodiesel fuel blends at low temperature. International Journal of ..., 13(2), 293-300. https://doi.org/10.1007/s12239

[5] Kumar, M. L. S. D., Drakshayani, S., \& Reddy, K. V. K. (2012). Effect of Fuel Injection Pressure on Performance of Single Cylinder Diesel Engine at Different Intake Manifold Inclinations. International Journal of Engineering and Innovative Technology, 2(4), 20-28. 
[6] Liaquat, A. M., Masjuki, H. H., Kalam, M. A., Varman, M., \&Hazrat, M. A. (2012). Experimental analysis on engine performance and emission characteristics using biodiesel obtained from non-edible oil. International Review of Mechanical Engineering, 6(3), 659-665.

[7] Student, M. T., \& Agricultural, P. (2012). Emission and Performance Characteristics of Jatropha Ethyl Ester Blends with Diesel Fuel in a C. I. Engine, 2(2), 34-47.

[8] Chen, L. Y., Chen, Y. H., Hung, Y. S., Chiang, T. H., \& Tsai, C. H. (2013). Fuel properties and combustion characteristics of Jatropha oil biodiesel-diesel blends. Journal of the Taiwan Institute of Chemical Engineers, 44(2), 214-220. https://doi.org/10.1016/j.jtice.2012.09.011

[9] El-kasaby, M., \&Nemit-allah, M. A. (2013). Experimental investigations of ignition delay period and performance of a diesel engine operated with Jatropha oil biodiesel. Alexandria Engineering Journal, 52(2), 141-149. https://doi.org/10.1016/j.aej.2012.12.006

[10] De, B., \&Panua, R. S. (2014). An experimental study on performance and emission characteristics of vegetable oil blends with diesel in a direct injection variable compression ignition engine. Procedia Engineering, 90, 431-438. https://doi.org/10.1016/j.proeng.2014.11.873

[11] Paul, G., Datta, A., \& Mandal, B. K. (2014). An experimental and numerical investigation of the performance, combustion and emission characteristics of a diesel engine fueled with Jatropha biodiesel. Energy Procedia, 54, 455-467. https://doi.org/10.1016/j.egypro.2014.07.288

[12] Rajneesh Kumar, Anoop Kumar Rathod (2012) Emission and execution attributes of Jatropha ethyl ester mixes with diesel fuel in a C.I. engine.

[13] HannyJohanesBerchmans, Shizuko Hirata (2007) Biodiesel generation from rough Jatrophacurcas L. Seed oil with a high substance of free unsaturated fats.

[14] Jindal, S. (2011). Effect of injection timing on combustion and performance of a direct injection diesel engine running on Jatropha methyl ester. International Journal of Energy and Environment, 2(1), 113-122

[15] Chaudhari, S. G., Modi, M. A., Patel, T. M., \&Rathod, G. P. (2016). Performance of small capacity compression ignition engine using Jatropha biodiesel blends, 129-133.

[16] Modi, M. A., Patel, T. M., \&Rathod, G. P. (2014). Performance and Emission Analysis of Diesel Engine using palm seed oil and diesel blend, 11(2), 29-33.

[17] Patel, K. B., Patel, P. T. M., \& Patel, S. C. (2013). Parametric Optimization of Single Cylinder Diesel Engine for Pyrolysis Oil and Diesel Blend for Specific Fuel Consumption Using Taguchi Method, 6(1), 83-88.

[18] Prajapati, J. B., Panchal, P. R., \& Patel, T. M. (2014). Performance and Emission Characteristics of. I. Engine fueled With DieselBiodiesel Blends, 11(3), 114-121.

[19] Prajapati, H. N., Patel, T. M., \&Rathod, G. P. (2014). Emission analysis of biogas premixed charge diesel dual fueled engine, 4(5), 54-60.

[20] Jani, A., Patel, T., \&Rathod, G. (2015). Effect of Varying Load on Performance and Emission of C. I. Engine Using WPO Diesel Blend, 12(2), 37-44. https://doi.org/10.9790/1684-12253744 